Bangladesh J. Pl. Breed. Genet., 25(2): 33-40, 2012

\title{
GENETIC DIVERSITY IN LOCAL AROMATIC RICE (Oryza sativa L.) GENOTYPES
}

\author{
M. Ali, M. A. K. Mian, M. G. Rasul, M. A. Aziz Miah', M. Z. Alam ${ }^{2}$ and M. A. \\ Hossain $^{3}$ \\ Department of Genetics and Plant Breeding \\ Bangabandhu Sheikh Mujibur Rahman Agricultural University \\ Gazipur 1706, Bangladesh
}

\begin{abstract}
Genetic diversity was assessed for 66 local aromatic rice genotypes to identify parental genotypes having distant relationship through Mahalanobis's $D^{2}$ statistic. First six principal component axes above unity contributed $90.88 \%$ for variation among the genotypes. Yield per plant showed the highest contribution to total divergence followed by grain breadth, days to maturity and others. The genotypes under study were grouped into ten clusters. Clusters III and VII comprised of the maximum number (11) of genotypes when Cluster X possessed single genotype. The lowest inter genotypic distance was recorded between Kalijira-7 and Chinigura when the highest distance was observed between Elai and Rajbhog-2. The highest inter cluster distance was observed between clusters I and V while the shortest distance was carried by the clusters VII and IX. It revealed that the genotypes belonging to cluster I was far diverse from the genotypes under cluster V whereas the genotypes belonging to clusters VII and IX were least diverse. Among the genotypes, Oval Tapl, Sakkorkhora, Black, Dubsail, Rajbhog-2, Badshahbhog-8, Guamori, Elai, Kataribhog and BRRI dhan-38 might be selected from different clusters for different characters for future breeding program.
\end{abstract}

Key words: Aromatic rice (Oryza sativa L.), PCA, PCO, CVA, D² analysis, Bangladesh

\section{INTRODUCTION}

Among the major cereal crops, is unique for its adaptation. It can be grown in a wide range of agro ecological conditions from $53^{\circ} \mathrm{N}$ to $40^{\circ} \mathrm{S}$ latitude and from sea level to over $3000 \mathrm{~m}$ in the Himalayas ( $\mathrm{Lu}$ and Chang, 1980). Domestication of wild rice probably started about 9000 years ago (Khush, 2000). Asian and African farmers, mostly women selected different types to suit local condition and needs (Singh et al., 2000).

Aromatic rice constitutes a special group of rice which is considered best in quality. Though local aromatic rice varieties are low yielder, a good number of aromatic rice genotypes with appreciable grain quality and taste are present in Bangladesh. These could be excellent source of sound breeding program for aromatic rice in the country. However, increasing yield of aromatic rice through plant breeding techniques has several

\footnotetext{
${ }^{1}$ Former CSO, Biotechnology Division, Bangladesh Rice Research Institute, Gazipur 1701; Department of Entomology, Bangabandhu Sheikh Mujibur Rahman Agricultural University, Gazipur 1706; 3Plant Breeding Division, Bangladesh Rice Research Institute, Gazipur 1701, Bangladesh
} 
problems; one of them is genetic diversity, extensive use of small and medium grain aromatic rice provides viable alternatives to diversify aromatic rice gene pool.

Evaluation of genetic diversity is important to know the source of genes for a particular trait within the available germplasm. Precise information on the nature and degree of genetic divergence of the parents is the prerequisites of an effective breeding program. Genetic diversity could help to sustain long term selection gain (Chowdhury et al. 2002). But information on genetic diversity in Bangladeshi aromatic rice is not sufficient. Multivariate analysis is a useful tool in quantifying the degree of divergence between biological population at genotypic level and to assess relative contribution of different components to the total divergence both at intra- and inter-cluster levels (Jatasra and Parada, 1978; Zahan et al. 2008). Therefore, this research program was undertaken to assess genetic diversity in Bangladeshi local aromatic rice genotypes and to select suitable diverse parents for future breeding program.

\section{MATERIALS AND METHODS}

The experiment was conducted at Bangabandhu Sheikh Mujibur Rahman Agricultural University, Gazipur during T. Aman season (June to December) of 2007. Sixty six Bangladeshi local aromatic rice genotypes were used in the study. The experiment was laid out in a randomized complete block design (RCBD) with three replications. Size of each plot was $2.4 \mathrm{~m}^{2}$. Data were collected from each replication on number of tillers per plant, days to first flowering, days to $50 \%$ flowering, days to maturity, plant height $(\mathrm{cm})$, number of productive tillers per plant, panicle length $(\mathrm{cm})$, number of primary branches per panicle, number of spikelets per primary branch, number of secondary branches per panicle, number of spikelets per secondary branch, number of total spikelets per panicle, number of filled grains per panicle, 1000 grain weight (gm), yield per plant (gm), harvest index, grain length $(\mathrm{mm})$, grain breadth $(\mathrm{mm})$ and grain length-breadth ratio. Analysis of variance was done by computer using MSTAT-C software. Multivariate analysis was done by computer using GENSTAT 5.13 and Microsoft Excel 2000 software through different techniques viz. principal component analysis (PCA), principal coordinate analysis (PCO), cluster analysis and canonical vector analysis (CVA).

\section{RESULTS AND DISCUSSION}

A considerable genetic variability was observed among the genotypes after performing analysis of variance and thereby, diversity analysis was carried out through multivariate analysis. Eigen values and percentage of total variation accounted for them obtained from principal component analysis revealed that the first axis largely accounted for the variation among genotypes (51.29 \%) followed by the second axis (13.55\%) (Table1). First six eigen values above unity accounted for $90.88 \%$ while only first two values accounted for $64.84 \%$ variation. Shiv et al. (2003) also showed that $64 \%$ variation was observed in first two values.

\section{Cluster analysis}

By application of non hierarchical clustering using covariance matrix, the sixty six genotypes were grouped into ten different clusters (Table 2). Cluster III and cluster VII contained the maximum number of eleven genotypes followed by cluster VI and cluster IX having eight genotypes each and cluster II having seven genotypes respectively. Cluster X possessed a single genotype. These results were in conformity with the clustering pattern obtained through principal component analysis. Similarly, 
Jadhav et al. (2003) grouped 49 rice cultivars into nine clusters based on genetic distance. Canonical variate analysis was done to compute the intra and inter cluster distances (Table 2). Result indicated that the inter cluster distance were larger than intra cluster distance in most of the cases suggesting wider genetic diversity among the genotypes of different groups. Singh et al. (1987) also reported about the cluster by using $\mathrm{D}^{2}$ statistics.

Table 1. Eigen values and percentage of variation for 19 principal components axes in 66 local aromatic rice genotypes

\begin{tabular}{c|c|c|c}
\hline $\begin{array}{c}\text { Principal component } \\
\text { axes }\end{array}$ & Eigen values & $\begin{array}{c}\text { Total variation } \\
\text { accounted for }(\%)\end{array}$ & $\begin{array}{c}\text { Cumulative variation } \\
(\%)\end{array}$ \\
\hline A & 12.575 & 51.29 & 51.29 \\
B & 3.322 & 13.55 & 64.84 \\
C & 2.453 & 10.01 & 74.85 \\
D & 1.617 & 6.59 & 81.44 \\
E & 1.203 & 4.91 & 86.35 \\
F & 1.111 & 4.53 & 90.88 \\
G & 0.534 & 2.18 & 93.06 \\
H & 0.482 & 1.97 & 95.03 \\
I & 0.368 & 1.5 & 96.53 \\
J & 0.261 & 1.06 & 97.59 \\
K & 0.198 & 0.81 & 98.4 \\
L & 0.169 & 0.69 & 99.09 \\
M & 0.088 & 0.36 & 99.45 \\
N & 0.059 & 0.24 & 99.69 \\
O & 0.040 & 0.16 & 99.85 \\
P & 0.015 & 0.06 & 99.91 \\
Q & 0.013 & 0.05 & 99.96 \\
R & 0.006 & 0.02 & 99.98 \\
S & 0.003 & 0.01 & 99.99 \\
\hline
\end{tabular}

Table 2. Distribution of 66 local aromatic rice genotypes into ten clusters

\begin{tabular}{|c|c|c|}
\hline Cluster & $\begin{array}{c}\text { Number of } \\
\text { genotypes }\end{array}$ & Name of genotypes \\
\hline I & 06 & $\begin{array}{l}\text { Badshabhog-6, Badshabhog-8, Doiargura, Guamori, Premful and } \\
\text { Rajbhog-2 }\end{array}$ \\
\hline II & 07 & $\begin{array}{l}\text { Agali, Badshabhog-7, Chinigura, Duksail, Kalijira-7, Kalijira-8 and } \\
\text { Uknimadhu }\end{array}$ \\
\hline III & 11 & $\begin{array}{l}\text { Awned-1, Benaful, Chinikamini, Dakshahi, Kalijira-5, Kalijira-9, } \\
\text { Kalijira-11, Kalijira-12, Radhunipagal-3, Saibail and Thakurbhog }\end{array}$ \\
\hline IV & 06 & $\begin{array}{l}\text { Basmati-2, BRRI Dhan-5, Hatishail, Kataribhog, Keora, and } \\
\text { Rajbhog-1 }\end{array}$ \\
\hline $\mathrm{V}$ & 05 & Elai, Kalijira-6, Maloti-2, Kalgochi and Buchi \\
\hline VI & 08 & $\begin{array}{l}\text { Badshabhog-9, Black, Chinisakkor-2, Dubsail, Jirabhog finer, } \\
\text { Kalijira-13, Oval Tapl and Sakkorkhora }\end{array}$ \\
\hline VII & 11 & $\begin{array}{l}\text { Badshabhog (colored), Badshabhog-3, Badshabhog-5, Badshabhog- } \\
\text { 10, Basmati-1, BRRI Dhan-37, Chinisakkor-1, Kalijira finer, } \\
\text { Kalijira-10, Sorukamini-2 and Radhunipagal-1 }\end{array}$ \\
\hline VIII & 03 & Badshabhog-4, BRRI Dhan-34 and Radhunipagal-2 \\
\hline IX & 06 & $\begin{array}{l}\text { Badshabhog-11, Kalijira-1, Kalijira-2, Kalijira-3, Kalijira-4, Khasa, } \\
\text { Maloti-1 and Sorukamini-1 }\end{array}$ \\
\hline $\mathrm{X}$ & 01 & BRRI Dhan-38 \\
\hline
\end{tabular}


Intra cluster distances were computed by using the values of inter genotype distances from distance matrix of PCO. There were no marked variations in intra-cluster distances which ranged from 0.000 to 0.917 (Table 3). Intra cluster distances in all clusters were more or less low which indicated genotypes within the same cluster were closely related. The highest intra cluster distance was computed for cluster $\mathrm{V}$ followed by the cluster IV. The intra-cluster distance in cluster $\mathrm{X}$ was zero since it was consisted of single genotype. The genotypes under cluster $\mathrm{V}$ were most heterogeneous and genotypes under cluster VIII (with the second lowest intra cluster distance) were comparatively homogenous.

Table 3. Average intra (Diagonal) and inter cluster $\mathrm{D}^{2}$ values for 66 local aromatic rice genotypes

\begin{tabular}{c|ccc|c|c|c|c|c|c|c|c}
\hline Cluster & I & II & III & IV & V & VI & VII & VIII & IX & X \\
\hline I & $\mathbf{0 . 3 9 3}$ & & & & & & & & & \\
II & 10.347 & $\mathbf{0 . 7 2 8}$ & & & & & & & \\
III & 13.790 & 5.469 & $\mathbf{0 . 6 7 9}$ & & & & & & & \\
IV & 15.108 & 7.12 & 5.54 & $\mathbf{0 . 9 1 3}$ & & & & & & \\
V & 18.647 & 9.826 & 6.718 & 5.359 & $\mathbf{0 . 9 1 7}$ & & & & & \\
VI & 8.537 & 3.641 & 6.139 & 8.294 & 11.243 & $\mathbf{0 . 7 0}$ & & & & \\
VII & 8.066 & 4.424 & 6.876 & 7.906 & 11.622 & 3.658 & $\mathbf{0 . 5 8 8}$ & & & \\
VIII & 5.384 & 8.654 & 11.665 & 12.258 & 15.846 & 6.763 & 5.828 & $\mathbf{0 . 3 5 8}$ & & \\
IX & 6.127 & 5.064 & 8.671 & 10.295 & 13.712 & 4.365 & 3.545 & 5.501 & $\mathbf{0 . 4 6 9}$ & \\
X & 12.282 & 10.669 & 10.984 & 11.428 & 14.957 & 8.942 & 8.545 & 10.674 & 9.995 & $\mathbf{0 . 0}$ \\
\hline
\end{tabular}

Statistical distances obtained through canonical vector analysis represented the index of genetic diversity among the clusters. Inter-cluster distance was maximum between clusters I and V (18.647) and minimum between clusters VII and IX (3.545) (Table 2). The maximum value of inter cluster distance indicated that genotypes belonging to cluster I was far diverged from those of cluster V. The inter cluster distances in all the clusters were higher than the intra cluster distances reflecting wider diversity among genotypes of different clusters. The results are in agreement with Singh et al. (1996) and Bashar et al. (2007). Genotypes belonging to the distant clusters could be used in hybridization program for obtaining a wide spectrum of variation among the segregates (Mokate et al., 1998). It is more beneficial if crossing might be carried out between genotypes belonging to different groups if their genetic distances $\left(\mathrm{D}^{2}\right)$ are greater than 12.5 (Wei et al., 1994).

\section{Cluster means for the characters}

The mean performances of 19 characters in ten clusters are shown in table 4 . Most of the characters showed distinct difference among the clusters. In cluster I, it contained the highest mean values for the character number of total spikelets per panicles, number of filled grains per panicle and harvest index. While it produced the lowest mean for the characters number of tiller per plant, number of productive tillers per plant, 1000 grain weight, yield per plant and grain breadth. Cluster II produced the highest cluster mean for the character plant height with no lowest cluster mean value. Cluster III had the maximum cluster mean for the character days to first flowering, days to $50 \%$ flowering and days to maturity and the lowest for the character harvest index.

Cluster IV comprised the highest cluster mean for grain length-breadth ratio and the lowest cluster mean for days to first flowering, days to 50\% flowering and panicle length. Cluster V had the maximum range of variability for the characters 1000 grain weight, yield per plant, grain length and grain breadth where as it gave the lowest cluster. 
Table 4. Cluster mean for nineteen characters in 66 local aromatic rice genotypes

\begin{tabular}{|c|c|c|c|c|c|c|c|c|c|c|}
\hline \multirow[t]{2}{*}{ Character } & \multicolumn{10}{|c|}{ Cluster } \\
\hline & I & II & III & IV & $\mathbf{V}$ & VI & VII & VIII & IX & $\mathbf{X}$ \\
\hline Number of tillers per plant & 14.58 & 16.38 & 16.07 & 15.69 & 016.41 & 16.65 & 16.45 & 15.71 & 16.25 & 24.17 \\
\hline Days to 1 st flowering & 105.05 & 107.52 & 110.27 & 103.28 & 107.27 & 108.29 & 107.61 & 106.44 & 105.08 & 108.00 \\
\hline Days to $50 \%$ flowering & 109.56 & 112.24 & 115.70 & 108.06 & 111.80 & 113.71 & 112.57 & 111.44 & 110.58 & 113.33 \\
\hline Days to maturity & 144.78 & 146.81 & 150.18 & 144.61 & 147.87 & 148.46 & 146.55 & 145.55 & 145.92 & 144.33 \\
\hline Plant height $(\mathrm{cm})$ & 141.18 & 148.50 & 143.07 & 121.19 & 135.39 & 140.57 & 130.93 & 128.83 & 144.69 & 107.11 \\
\hline Number of productive tillers per plant & 9.72 & 11.46 & 11.17 & 10.55 & 10.94 & 11.30 & 11.58 & 11.03 & 11.32 & 13.93 \\
\hline Panicle length $(\mathrm{cm})$ & 26.98 & 26.41 & 27.30 & 22.91 & 26.17 & 28.47 & 23.78 & 24.11 & 25.29 & 26.50 \\
\hline Number of primary branches per panicle & 11.77 & 11.98 & 11.82 & 10.52 & 10.05 & 12.06 & 10.29 & 11.21 & 11.65 & 10.87 \\
\hline Number of spikelets per primary branch & 29.45 & 25.19 & 20.85 & 21.64 & 19.05 & 27.51 & 25.60 & 36.58 & 28.36 & 18.00 \\
\hline Number of secondary branches per panicle & 56.86 & 55.10 & 45.63 & 40.11 & 37.05 & 60.29 & 46.54 & 55.07 & 49.30 & 48.30 \\
\hline Number of spikelets per secondary branch & 5.80 & 05.22 & 04.42 & 04.44 & 3.83 & 5.23 & 5.33 & 6.10 & 6.06 & 3.87 \\
\hline Number of total spikelets per panicle & 232.64 & 196.42 & 166.68 & 166.23 & 141.36 & 198.89 & 199.47 & 215.23 & 211.29 & 188.43 \\
\hline Number of filled grains per panicle & 192.40 & 144.11 & 138.11 & 129.82 & 116.91 & 159.52 & 160.19 & 181.32 & 165.62 & 165.83 \\
\hline 1000 grain weight $(\mathrm{g})$ & 11.94 & 16.38 & 17.20 & 18.47 & 25 & 15.72 & 13.56 & 12.09 & 13.18 & 12.65 \\
\hline Yield per plant $(\mathrm{g})$ & 21.97 & 26.45 & 25.91 & 24.25 & 30.84 & 26.94 & 24.14 & 23.24 & 24.42 & 29.96 \\
\hline Harvest index & 0.50 & 0.44 & 0.42 & 0.47 & 0.49 & 0.48 & 0.46 & 0.5 & 0.49 & 0.44 \\
\hline Grain length (mm) & 5.606 & 6.745 & 6.413 & 7.651 & 7.963 & 5.957 & 5.945 & 5.57 & 6.03 & 5.397 \\
\hline Grain bredath (mm) & 2.250 & 2.676 & 2.703 & 2.488 & 3.054 & 2.787 & 2.355 & 2.373 & 2.411 & 2.424 \\
\hline Grain length-breadth ratio & 2.460 & 2.517 & 2.425 & 3.184 & 2.687 & 2.164 & 2.56 & 2.35 & 2.506 & 2.227 \\
\hline
\end{tabular}


mean for number of primary branches per panicle, number of secondary branches per panicle, number of spikelets per secondary branch, number of spikelets per panicle and number of filled grains per panicle. Cluster VI possessed highest cluster mean for panicle length, number of primary branches per panicle and number of secondary branches per panicle and the lowest cluster mean for grain length-breadth ratio.

Cluster VIII produced the highest mean for number of spikelets per primary branch, number of spikelets per secondary branch and harvest index. The highest cluster mean for number of tillers per plant and number of productive tillers per plant was observed in cluster $\mathrm{X}$ while this cluster produced the lowest cluster mean for day to maturity, plant height, number of spikelets per primary branch and grain length.

\section{Contribution of characters towards divergence of the genotypes:}

Contribution of characters towards divergence of the genotypes is presented in Table 5. Yield per plant, grain breadth, days to maturity, days to first flowering, days to $50 \%$ flowering, number of tillers per plant, number of productive tillers per plant and panicle length for vector I and vector II had positive value which indicated that they were the important component having higher contribution to the genetic divergence among genotypes studied. With few exceptions, Bidhan et al. (2002), Bashar et al. (2007) and Rahim et al. (2007) also showed that positive value of vector I and II in case of number of tillers per plant and panicle length.

\section{Selection of parent for future hybridization}

The crossed involving parents belonging to maximum divergent clusters were expected to manifest maximum heterosis and also wide genetic variability. A higher heterosis could be produced from the crosses between genetically distant parents (Ghaderi et al., 1984). Keeping this in view, it appears that crosses between genotypes belonging to cluster I and V would give high manifestation of heterosis as well as wide spectrum of genetic variation in $\mathrm{F}_{2}$ generation.

Table 5. Relative contributions of nineteen characters of local aromatic rice genotypes to the total divergence

\begin{tabular}{l|c|c}
\hline Character & Vector-I & Vector II \\
\hline Number of tillers per plant & 0.074 & 0.126 \\
Days to 1st flowering & 0.099 & 0.392 \\
Days to 50\% flowering & 0.096 & 0.416 \\
Days to maturity & 0.158 & 0.348 \\
Plant height (cm) & -0.064 & 0.227 \\
Number of productive tillers per plant & 0.029 & 0.100 \\
Panicle length (cm) & 0.038 & 0.296 \\
Number of primary branches per panicle & -0.084 & 0.304 \\
Number of spikelets per primary branch & -0.350 & -0.012 \\
Number of secondary branches per panicle & -0.271 & 0.265 \\
Number of spikelets per secondary branch & -0.326 & -0.045 \\
Number of total spikelets per panicle & -0.369 & 0.047 \\
Number of filled grains per panicle & -0.337 & 0.035 \\
1000 grain weight (gm) & 0.361 & -0.040 \\
Yield per plant (gm) & 0.281 & 0.056 \\
Harvest index & -0.088 & -0.163 \\
Grain length (mm) & 0.298 & -0.215 \\
Grain breadth (mm) & 0.264 & 0.180 \\
Grain length-breadth ratio & 0.102 & -0.330 \\
\hline
\end{tabular}


Genotypes included in Cluster I was important for number of total spikelets per panicle, number of filled grains per panicle and harvest index, cluster II for plant height, cluster III for days to first flowering, days to $50 \%$ flowering and days to maturity, cluster IV for grain length-breadth ratio, cluster V for 1000 grain weight, Yield per plant, grain length, grain breadth, cluster VI for panicle length, number of primary branches per panicle, number of secondary branches per panicle, cluster VIII for number of spikelets per primary branch, number of spikelets per secondary branch, harvest index and cluster $\mathrm{X}$ for number of tillers per plant and number of productive tillers per plant.

It was found that different genotypes performed better in desirable direction for different characters. Considering the magnitude of genetic distance, cluster mean and per se performance, Rajbhog-2, Kataribhog, Oval Tapl, Sakkorkhora, Badshabhog-8, Dubsail, Elai, Guamori, Black and BRRI Dhan -38 might be selected for future hybridization program from different clusters. Similarly, after assessing genetic diversity in rice genotypes, Arun et al. (2002) and Rahim et al. (2007) identified some genotypes as suitable for future breeding program.

\section{REFERENCES}

Arun, S., D. V. Yadav, A. K. Singh, Y. Gaurav, G. Surinde, K. R. Gupta, S. Ranghvirendra, P. Deepak, A. Sharma, G. Yadav, S. Gulia, R. Singh and D. Prem. 2002. Genetic divergence in aromatic rice (Oryza sativa L.). National Journal of Plant Improvement. 4(2): 46-49.

Bashar, M. K., M. A. K. Mian, M. Nasiruddin., Nur-E-Elahi, A. W. Julfiquar and M. G. Rasul. 2007. Genetic divergence based on morphophysiological characters of some maintainer and restorer lines in rice (Oriza sativa L.). In Proce of the 7th Biennial Conference of Plant Breeding and Genetics Society of Bangladesh held on May 26, 2007 at Bangladesh Rice Research Institute, Gazipur. 72p.

Bidhan, R., A. K. Basu, A. B. Manda and B. Roy. 2002. Genetic diversity in rice (Oryza sativa L.) Genotypes under humid tropic of Andaman based on grain yield and seed characters. Indian Journal of Agricultural Sciences. 72(2): 84-87.

Chowdhury, M. A., V. Vandenberg and T. Warkentin. 2002. Cultivar identification and genetic relationship among selected breeding lines and cultivars in chickpea (Cicer arietinum L). Euphytica. 127(3): 317-325.

Ghaderi, A., M. Shishegar, A. Regai and B. Ehdaie. 1984. Multivariate analysis of genetic diversity for yield and its components in mungbean. Journal of American Society of Horticultural Science. 104: 728-732.

Jadhav, P., A. K. Sarawgi., L. K. Mishra and J. Pravin. 2003. Studied on genetic diversity in rice genotype (Oryza sativa L.). Plant Archives. 3(1): 15-19.

Jatasra, D. S. and R. S. Parada. 1978. Genetic divergence in wheat under different environmental conditions. Cereal Research Communication. 6: 307-317.

Khush, G. S. 2000. Taxonomy and origin of rice. In Aromatic rices (Singh, R.K., Singh, U. S., Khush-GS. Eds.). Oxford and IBS publishing Co. Ltd., New Delhi, India. 5-14pp.

Lu, J. and T. T. Chang. 1980. Rice in its temporal and spatial perspectives. In : B.S. Luh (ed). Rice production and utilization. Avi, Davis, California. 1-74pp.

Mokate, A. S., S. S. Mehetre, V. W. Bendale and S. P. Birari. 1998. Genetic divergence in rice. Adv. Sci. 11(2): 189-192.

Rahim, M. A., M. S. Hossain and M. S. R. Bhuiyan. 2007. Characterization and genetic diversity analysis in rice (Oriza sativa L.). In Proc. of the 7th Biennial 
Conference of Plant Breeding and Genetics Society of Bangladesh held on May 26, 2007 at Bangladesh Rice Research Institute, Gazipur. 50pp.

Shiv, D., S. C. Dani and S. Datt. 2002. Genetic divergence in elite genotypes of basmati rice (Oryza sativa L.). Indian Journal of Genetics and Plant Breeding. 63(1): 73-74.

Singh, R. P., D. P. Singh and B.D. Chaudhury. 1987. Morphological variation in Indian mustard. Annals of Biology. 3(1): 26-31.

Singh, R. K., P. L. Gautam, S. Sanjcev and S. Singh. 2000. Scented Rice Germplasm: Conservation, evaluation and Utilization. In Aromatic rices (Singh, R.K., Singh, U. S., Khush, G. S. Eds.). Oxford and IBS publishing Co. Ltd., New Delhi, India. 107-134 pp.

Singh, S. K., R. S. Singh and S.M. Singh. 1996. Genetic divergence in scented and fine genotypes of rice (Oryza sativa L.) Annals of Agricultural Research. 17(2): 163-166.

Wei, W. X., H. Zhang, F. Y. Lu and S. L. Wei. 1994. Principal component analysis and genetic distance estimation and their application in sesame breeding programme. Acta Agric. Boreali Sinica. 9(3): 29-33.

Zahan, M. I., M. S. R. Bhuiyan, and M. S. Hossain. 2008. Genetic divergence in Oleiferous Brassica species. Journal of Shere-Bangla Agricultural University. 2(1): 1-6. 